\title{
The structure and function of giraffe jugular vein valves
}

\author{
Graham Mitchell $^{1,2}$, Sybrand J. van Sittert ${ }^{1^{*}}$ \& John D. Skinner ${ }^{1}$ \\ ${ }^{1}$ Centre for Veterinary Wildlife Studies, Faculty of Veterinary Science, University of Pretoria, Private Bag X04, \\ Onderstepoort, 0110 South Africa \\ ${ }^{2}$ Department of Zoology and Physiology, University of Wyoming, 1000 E University Avenue, Laramie, WY 82072, U.S.A. \\ Received 8 October 2008. Accepted 26 October 2009
}

\begin{abstract}
When a giraffe (Giraffa camelopardalis) lowers its head to drink, blood could enter the jugular vein from the inferior vena cava or regurgitate from the jugular veins into the cranial veins. We investigated the anatomy of jugular valves in giraffes to establish if they could prevent either of these regurgitations. Jugular vein length and intervalve distances of 396 valves (192 left, 204 right) were measured in 60 veins from 25 adult (11 males and 14 females) and five foetal giraffes. The average number of valves in the left jugular veins was $6.4 \pm 2.7$ (mean \pm S.D.; range $=2-13$ ) and in the right was $6.8 \pm 2.1$ (range $=3-12$ ). Male giraffes had $7.3 \pm 2.7$, females $5.9 \pm 2.1$, and foetuses $7.0 \pm 2.1$ valves per vein. None of these differences was statistically significant ( $t$-test; $P>0.05)$. Most valves $(88 \%)$ were bicuspid in structure. Their position in the veins was irregular. Most (36.1\%) were located in the first $500 \mathrm{~mm}$ of vein. The relative distribution of foetal valves was not significantly different from that in adult giraffes $\left(\chi^{2}=0.274, P>0.05\right)$. We concluded that the main function of the jugular vein valves is to prevent regurgitation of blood from the inferior vena cava and right atrium into the jugular vein and that the number of valves is fixed in utero.
\end{abstract}

Key words: giraffe, jugular vein, valves.

\section{INTRODUCTION}

It is generally accepted that the function of jugular vein valves is to prevent cephalad flow of venous blood (Silva et al. 2002). In humans it is rare for blood in the jugular vein to flow towards the head. This occurs only when intrathoracic pressure increases sharply (for example during episodes of coughing) or when the person is standing on his/her head. Humans have only one jugular valve between the heart and the brain, perhaps reflecting its relative unimportance (Silva et al. 2002). In ruminants, however, the circumstances are the reverse. In them the head down position is a frequent, if not common, posture, and as a result they have to resolve two blood flow problems. First, the blood pressure in arteries supplying the head and brain increases under the influence of gravity. Secondly, there is a tendency for blood returning to the heart from the trunk to flow into the jugular vein and for blood in the jugular vein to flow towards the head. The magnitude of these effects is proportional to the length of the neck and the mechanisms that regulate them should, therefore, be most highly developed in giraffes (Giraffa camelopardalis).

In giraffes, control of the effects of high arterial blood pressure on extracranial blood vessels of

*To whom correspondence should be addressed.

E-mail: mitchg@uwyo.edu the head is achieved by the inelastic facial skin (Mitchell \& Skinner 1993, 2005). Its effects on brain blood vessels are controlled by the carotid rete, which dampens cerebral blood pressure and flow (Lluch et al. 1985; Mitchell \& Skinner 1993). Control of venous reflux is assumed to be the function of jugular vein valves, as their structure suggests that they are open when the head is higher than heart level and closed when the head is below heart level. However, the anatomy and position of the valves are largely unknown. We could find no reports of their structure or function in ruminants and there are only three reports on their anatomy in giraffes. These three descriptions were based on the study of few veins, and the results reported were inconsistent.

Amoroso et al. (1947) reported that "[the jugular vein] was a large straight vessel with five tricuspid valves of the usual type set at irregular intervals along it. All its tributaries were relatively very small and no valves were present at the orifices of any.' Goetz \& Keen (1957) noted that the single jugular vein they studied contained a 'large number' of bicuspid and tricuspid valves and that each of the tributaries flowing into the jugular vein was provided with a competent set of valves. These two reports suggested that there were two kinds of valves in two different positions. One type lies at 
the opening of tributaries, and the other type occurs independently of tributaries and is found at irregular distances along the length of the jugular. Hargens et al. (1987) reported that 'The existence of closely spaced valves in the head and distal neck as compared to sparse valves in the proximal neck indicates their importance for preventing retrograde venous flow, for example during short periods when the giraffes head is lowered below heart level during drinking.' This description implies that the distribution of the valves is not random, nor irregular, and has a purpose.

Thus there is no consensus about where the valves are, whether they are tri- or bi-cuspid, how many there are, or what their function might be. We report here an analysis of jugular vein and valve anatomy in giraffes in order to resolve this uncertainty.

\section{METHODS}

\section{Animals}

Giraffes (11 males and 14 females) ranging in age from juveniles (body mass $\sim 200 \mathrm{~kg}$ ) to mature adult males (body mass $\sim 1500 \mathrm{~kg}$ ), and five foetal (5 males) giraffes, were obtained from culling operations in southeastern Zimbabwe during 2007 and 2008.

\section{Anatomical measurements}

In giraffes the left and right jugular veins are single, not double, as they are in other ruminants (Joly \& Lavocat 1846; Lawrence \& Rewell 1948). After removal of neck skin from the giraffes, the jugular vein on each side was exposed and the junction of the internal and external maxillary veins located. Each jugular vein was opened from this point to its junction with the superior vena cava and this distance defined the length of each vein. The number of valves was recorded; their position in relation to tributaries was measured, as was the distance between each valve, their position in relation to the length of the veins, and their distance from the superior vena cava. The structure (bi- or tricuspid) of 85 valves in seven animals (14 veins) was noted, as was the position of each of these types of valve in the veins.

Jugular vein length and intervalve distances were 'normalized' to allow comparison of the position of the valves and intervalve distances as if all jugular veins were exactly the same length. Normalized distances were calculated to a standard vein length of $2000 \mathrm{~mm}$, by multiplying actual vein length and intervalve distances by a factor calculated from
[2000 $\mathrm{mm} \div$ actual length]. Thus for a vein $2350 \mathrm{~mm}$ long the factor was $(2000 \div 2350)$ or 0.85 and the 'normalized' length was $2350 \mathrm{~mm} \times 0.85$. Each intervalve distance was reduced by the factor appropriate for vein length. For veins shorter than $2000 \mathrm{~mm}$, for example a jugular vein $1500 \mathrm{~mm}$ long, the 'normalized' length was $1500 \times$ $1.33 \mathrm{~mm}(2000 \div 1500=1.33)$ and each intervalve distance was increased by a factor of 1.33 .

To determine if the number of valves, and intervalve distances changed during growth we compared measurements made in foetal giraffes with those in postnatal animals, using normalized lengths. We also used the increase in intervalve distance as a measure of neck growth to assess whether neck elongation in giraffes was uniform throughout its length.

\section{Data analysis}

Student's two-sample $t$-test assuming unequal variances was used to compare the mean number of valves in the left and right jugular veins and between male and female giraffes. Correlation between the number of valves and the length of vein was analysed by linear regression. The chi-square test was used to analyse whether expected and observed numbers of valves in each segment of jugular vein were similar. $P$ values < 0.05 were regarded as significant.

No institutional animal care approval was required for this study. Animals were culled according to the legal requirements of Zimbabwe.

\section{RESULTS}

\section{Jugular length}

Our data were obtained from measurements made in 60 jugular veins in situ. The actual lengths of the jugular veins are summarized in Table 1. There were no significant differences in length between male and female veins $\left(t_{22}=1.615\right.$, $P>0.05)$. Of the 50 veins in the post-natal animals, 28 were from mature animals (males $>1000 \mathrm{~kg}$ body mass, females $>800 \mathrm{~kg}$ ), and the length of these jugular veins was $2000.8 \pm 176.5 \mathrm{~mm}$ (mean \pm S.D.). The average length of the 10 foetal veins was $542.4 \pm 47.7 \mathrm{~mm}$, thus foetal veins elongate approximately four fold after birth.

\section{Valve structure}

We analysed the type of valve in 14 jugular veins from seven giraffes. There were 85 valves in these veins of which $88.2 \%(75 / 85)$ were bicuspid and $11.8 \%$ were tricuspid in form. In only three of the 14 
Table 1. Jugular vein lengths (mean \pm S.D.) in 11 adult male, 14 adult female and five foetal giraffes.

\begin{tabular}{lccr}
\hline Gender & Side & Length $(\mathrm{mm})$ & Range $(\mathrm{mm})$ \\
\hline Males & $\mathrm{L}$ & $1760.9 \pm 536.4$ & $900-2369$ \\
\multirow{2}{*}{ Females } & $\mathrm{R}$ & $1779.9 \pm 515.3$ & $905-2315$ \\
& $\mathrm{~L}$ & $1644.4 \pm 270.1$ & $1000-2010$ \\
Males and females & $\mathrm{R}$ & $1710.5 \pm 298.2$ & $1055-2120$ \\
Foetus & $\mathrm{L}$ & $1698.8 \pm 408.3$ & $900-2369$ \\
& $\mathrm{R}$ & $1742.3 \pm 403.8$ & $905-2315$ \\
& $\mathrm{~L}$ & $542.4 \pm 46.3$ & $475-590$ \\
& $\mathrm{R}$ & $542.4 \pm 49.1$ & $480-600$ \\
\hline
\end{tabular}

veins we studied $(21 \%)$ were tricuspid valves found. The distribution of tricuspid and bicuspid valves between left and right veins was the same. The position of tricuspid valves was not consistent. Three of the 10 tricuspid valves were found at the proximal (caudal) end of the veins and the other seven nearer to the distal (rostral) end.

\section{Valve number}

We found 396 valves (192 left, 204 right) in the 60 veins we studied. The average number of valves in the left jugular veins was $6.4 \pm 2.7$ (mean \pm S.D.; range $=2-13, n=23$ ) and in the right was $6.8 \pm 2.1$ (range $=3-12$ ). The mode was 7 . These two means were not significantly different $\left(t_{28}=1.6, P>0.05\right)$. The average number of valves per vein in male giraffes was $7.3 \pm 2.5$, in females $5.9 \pm 2.1$, and in foetuses $7.0 \pm 2.1$. These differences also were not significant. There was no relationship between jugular length and the number of valves. In the left jugular veins the correlation coefficient $(r)$ between length and number was $0.2002(P>0.05)$ and in the right jugular veins it was $0.1550(P>0.05)$. For both sides combined it was 0.1805 .

\section{Valve position}

The position of individual valves in each jugular vein was highly irregular and could be described as random. For example the position of the sixth valve varied between $\sim 600 \mathrm{~mm}$ from the junction of the jugular vein with the superior vena cava and $1500 \mathrm{~mm}$ from it. The two most consistent findings were, first, that the most caudal (proximal) valve was $91 \pm 70$ and $87 \pm 57 \mathrm{~mm}$ from the superior vena cava in the left and right jugular veins respectively. Second, the number of valves in each $200 \mathrm{~mm}$ segment of foetal jugular vein was proportionately the same as in each $800 \mathrm{~mm}$ segment of normalized adult jugular length (Fig. 1).

In foetal veins $48.6 \%$ (34) of the valves occurred in the first $200 \mathrm{~mm}$ segment of the vein, $38.6 \%$ in the second segment and $12.9 \%$ in the third. In the mature animals the proportions were $50.6 \%$ (160 valves) in the first $800 \mathrm{~mm}, 37.7 \%$ in the second and $11.7 \%$ in the third. A chi-square test of these distributions showed that they were not significantly different $\left(\chi^{2}=0.223, P>0.05\right.$, d.f. $\left.=2\right)$. A similar analysis of the change in intervalve distance in each segment of the jugular veins (and therefore of each segment of the neck) during growth is shown in Table 2. The expected relative increase in mean intervalve distance was 3.8. Using the $\chi^{2}$ test the observed mean relative intervalve distances in adults were not significantly different from those in foetuses $\left(\chi^{2}=0.2201, P>0.05\right.$, d.f. $\left.=2\right)$. Intervalve distances were smallest in the proximal segment and largest in the distal segment.

Table 2. Intervalve distances in five foetal and 25 adult jugular veins.

\begin{tabular}{lcccc}
\hline $\begin{array}{l}\text { Segment } \\
(\mathrm{mm})\end{array}$ & $\begin{array}{c}\text { Foetus: mean intervalve } \\
\text { distance* }(\mathrm{mm})\end{array}$ & $\begin{array}{c}\text { Segment } \\
(\mathrm{mm})\end{array}$ & $\begin{array}{c}\text { Adult: mean intervalve } \\
\text { distance* }(\mathrm{mm})\end{array}$ & $\begin{array}{c}\text { Relative increase in } \\
\text { intervalve distance }\end{array}$ \\
\hline $0-200$ & 61.5 & $0-800$ & 235.7 & 3.83 \\
$200-400$ & 80.0 & $800-1600$ & 316.7 & 3.96 \\
$400+$ & 266.0 & $1600+$ & 894.1 & 3.36 \\
\hline
\end{tabular}

*Total segment length $\div$ average number of valves per segment.

${ }^{+}$Adult intervalve distance $\div$foetal intervalve distance. 


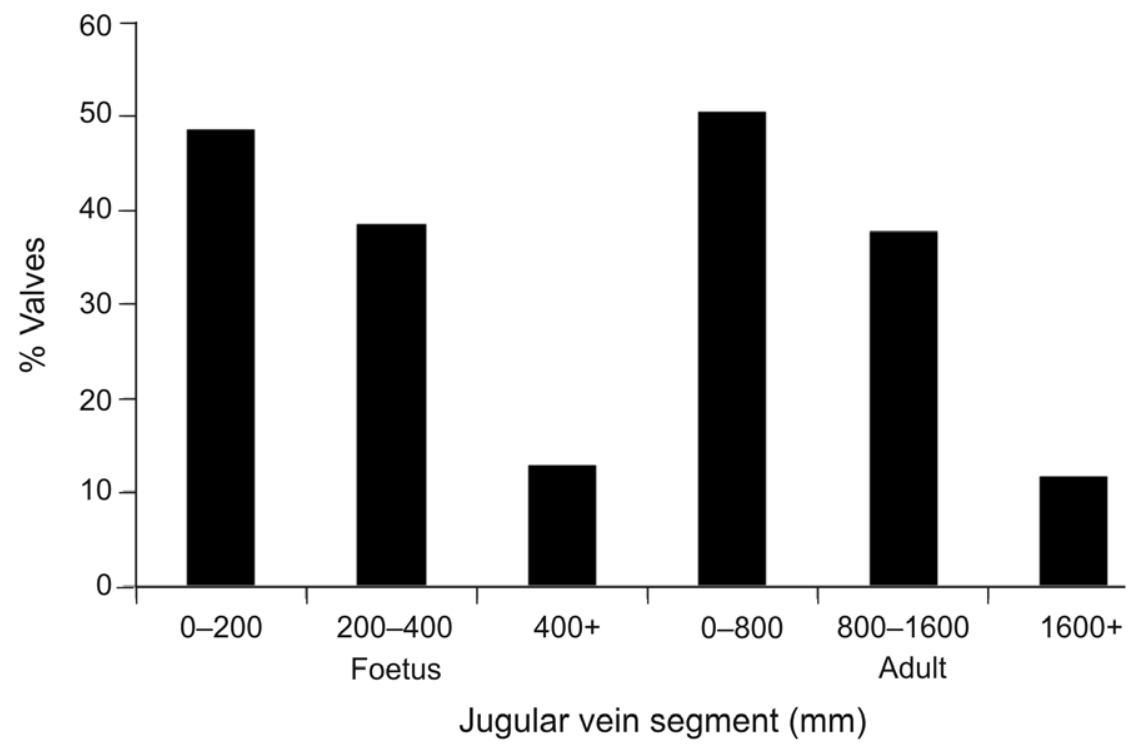

Fig. 1. Comparison between the number of valves per $200 \mathrm{~mm}$ segment of foetal jugular vein and in each $800 \mathrm{~mm}$ segment of adult jugular vein. Each $200 \mathrm{~mm}$ segment of foetal vein contains the same number of valves as each $800 \mathrm{~mm}$ segment of adult vein.

\section{Normalized veins}

The distribution of valves in veins of normalized length is analysed in Fig. 2. Most valves (36.1\%) were found at the bottom of the vein in the first $500 \mathrm{~mm}$, with $23.2 \%$ occurring in the next $500 \mathrm{~mm}$ segment, $24.0 \%$ in the next $500 \mathrm{~mm}$ segment, and $16.7 \%$ occurring in the top segment. In four giraffes there were no valves in the most distal (cranial) $500 \mathrm{~mm}$ of either the left or right jugular veins, nor in 11 of the left jugular veins, or eight of the right jugular veins.

\section{DISCUSSION}

When a giraffe lowers its head to drink, regurgitation of blood returning to the heart via the inferior vena cava must be prevented to maintain cardiac output. Regurgitation from the jugular vein and vertebral venous plexus towards the cranial circulations,

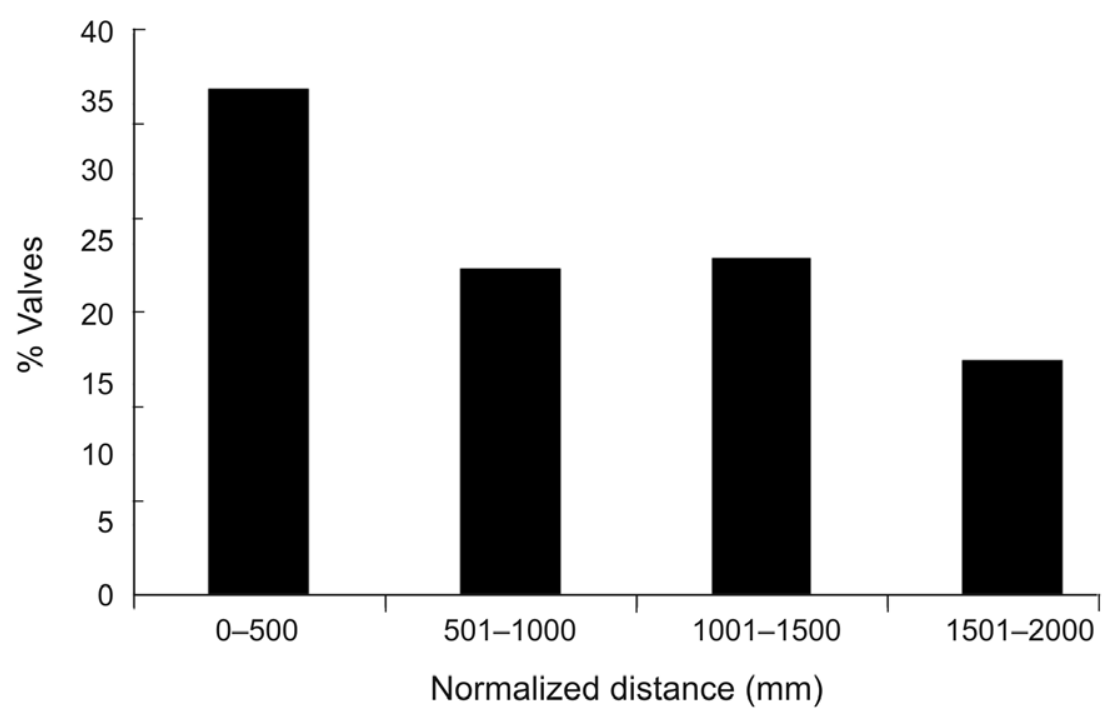

Fig. 2. Distribution of valves in each $500 \mathrm{~mm}$ segment of jugular vein normalized to a length of $2000 \mathrm{~mm} ; 36 \%$ of valves occur in the first $500 \mathrm{~mm}, 23 \%$ in the next $500 \mathrm{~mm}, 24 \%$ in the next $500 \mathrm{~mm}$ and $17 \%$ in the most distal $500 \mathrm{~mm}$. 
and regurgitation of blood from the jugular vein into its tributaries also must be prevented in order to prevent an increase in extra- and intracranial venous pressure. The volume of blood that could regurgitate theoretically is large. The volume of blood returning to the right atrium (venous return) from the trunk is approximately $95 \%$ of cardiac output (Mitchell \& Skinner 1993) or $\sim 5 \mathrm{l} / 100 \mathrm{~kg}$ of body mass per minute (Goetz et al. 1960) and could be $70 \mathrm{l} /$ minute in a mature giraffe. In two jugular veins each of $25 \mathrm{~mm}$ in diameter and $2 \mathrm{~m}$ long filled with blood, there are $2 \mathrm{I}$ of blood ( $1 \mathrm{I}$ in each). The volume of blood in the vertebral venous plexus is not known. Its volume, however, is relatively small and regurgitation from it into cerebral veins is likely to be prevented by changes in intracranial pressure (Mitchell et al. 2008).

Our data do not support the accepted idea that prevention of reflux of jugular blood into the extraor intracranial veins is the main function of the valves. The fewest valves occurred in the top of the vein, with many veins having no valves in the top $500 \mathrm{~mm}$ segment of the vein. This finding is contrary to that of Hargens et al. (1987) who reported that most valves were near the head. The absence of valves at the rostral end of the veins implies that blood in this part of the vein will regurgitate towards the cranial circulation. Even so, in our view, the amount of regurgitating blood would be small when a giraffe lowers its head. The average distance of the most rostral valve from the junction of the internal and external maxillary veins was $360 \mathrm{~mm}$. Thus in a jugular vein of $25 \mathrm{~mm}$ diameter the volume of blood in this section of the vein would be $\sim 200 \mathrm{ml}$ and $\sim 400 \mathrm{ml}$ if both veins were taken into account. This volume cannot be physiologically significant and in any case it is unlikely to enter the cranial veins because inspection of all the internal and external maxillary veins showed that each contained valves. In addition intracranial pressure increases when a giraffe lowers its head and offers resistance to regurgitation (Mitchell et al. 2008). Thus we do not support the idea that jugular vein valves have the general function in giraffes of preventing reflux of blood into the cranium proposed by Hargens et al. (1987).

Prevention of regurgitation of jugular blood into jugular vein tributaries is also not supported as a function of the jugular vein valves. None of the valves was located at or near the entry of tributary veins. Each tributary had its own valves, and it is these valves that prevent regurgitation into the tributaries. Our data do, however, provide an explanation for the two different interpretations of valve position reported by Amoroso et al. (1947) and Goetz \& Keen (1957). Our data suggest that Amoroso et al. were referring to the absence of jugular veins at the orifices of the tributaries, while Goetz \& Keen (1957) were referring to valves within the tributaries.

The most likely function of the valves is prevention of regurgitation of inferior vena cava and right atrial blood into the jugular vein when the giraffe is in the head down position. The anatomical structure of the valves is such that they are closed when the head is in the down position. Their effectiveness in preventing regurgitation will depend on their capacity to withstand the hydrostatic pressure generated by venous return and the column of blood in the jugular veins, and on their number, position, and structure.

The capacity of giraffe jugular valves to withstand back pressure has not been measured, but has been measured for giraffe axillary vein valves (Amoroso et al. 1947). Amoroso et al. (1947) established that the axillary vein valves could withstand back pressures of at least $200 \mathrm{~mm} \mathrm{Hg}$. The maximum back pressure in jugular veins of the length we have measured would be on average $175 \mathrm{~mm} \mathrm{Hg}$ if the veins were vertical and inverted. In reality the angle of the neck when a giraffe is drinking typically is $\sim 55^{\circ}$ to the vertical (Dagg 1962). Therefore, the maximum back pressure will be closer to $\sim 140 \mathrm{~mm} \mathrm{Hg}$ and well within the capacity of the valves to withstand it if they are as resilient as axillary vein valves. It is plausible that the effectiveness of the valves to prevent backflow is related to their structure, with tricuspid valves being better suited to resist pressure than bicuspid valves. However our data show that most ( 90\%) of the valves were bicuspid in structure, very few were tricuspid, and the position of the tricuspid valves was irregular with no consistent recognizable pattern. We therefore attached no functional significance to the number and distribution of tricuspid valves. Effectiveness of the valves also does not seem to depend on their number. The correlation coefficient between length and number was low: long jugular veins do not have or require more valves to be effective. In six veins there were just two or three valves and these presumably were just as effective as the 10 or more valves that were present in eight veins. Why so many valves are required to achieve their function is, therefore, not clear.

We do think, however, that effectiveness is 
related to valve position. We found that the first valve in the vein was in a consistent position of $\sim 100 \mathrm{~mm}$ from the junction with the superior vena cava, and that most valves were at the proximal end of the vein with fewest at the distal end, and this pattern was similar in all veins. We also found this pattern in a mature greater kudu (Tragelaphus strepsiceros) that we had the opportunity to examine. The length of the jugular veins in this animal was $\sim 700 \mathrm{~mm}$. The left vein contained nine valves and the right vein eight valves. Most valves $(41 \%)$ were in the bottom one-third of the veins, $35 \%$ were in the middle one-third, and $24 \%$ in the top one-third, mirroring the position in giraffes, and like giraffes (Table 1), intervalve distances were much closer in the bottom segment $(35.6 \pm 11.3 \mathrm{~mm}$, range $=23-53 \mathrm{~mm}$ ) than in the middle segment $(65.8 \pm 17.6$, range $=56-97 \mathrm{~mm})$ or the top segment $(206.8 \pm 109.9$, range $=111-360 \mathrm{~mm})$.

We tested whether valve position changed during maturation by comparing the number of valves per unit length of foetal jugular vein with the comparable length of adult jugular vein and found that the number in each $200 \mathrm{~mm}$ segment was the same as in each $800 \mathrm{~mm}$ of adult jugular vein. The number of valves in each segment in foetuses was the same as in adults, and so the number appears to be fixed in utero. After birth the position of the valves was determined by lengthening of the intervalve segments of the vein, so the relative position of the valves remains unchanged during growth. An interesting by-product of this analysis was that it suggested that there is no growth gradient in the neck as occurs in the giraffe appendicular skeleton (Thompson 1942). In the limbs the metapodials elongate more than proximal parts. Our data suggest that each segment of the giraffe neck elongates uniformly.

In summary, our data suggest that the main function of the jugular vein valves in giraffes is to direct the large amounts blood, returning to the heart via the inferior vena cava, into the right atrium, and to prevent its flow into the jugular vein. Prevention of regurgitation of the relatively small volume of blood in the jugular vein towards the head is achieved mainly by valves in the internal and external maxillary veins, assisted by the jugular valves. Engorgement of the muscles and soft tissues of the head by jugular blood is prevented by the valves at the orifice of the jugular tributaries. We also suggest that this general pattern and function of jugular valves probably is found in all ruminants.

\section{ACKNOWLEDGEMENTS}

We thank the management and staff of the Bubye Valley Conservancy, Zimbabwe, for their logistical support and sponsorship of this study. Additional funds were provided by the Don Craib Trust (JDS), from a personal research grant (J.D.S.) and the University of Wyoming (G.M.). S.J.v.S. is in receipt of Pretoria University bursary. Further technical field support was provided by Carl-Heinz Moeller, Kenneth Manyangadze, Mark Brewer, Andrew Henning, Lauren Leathem, Struan Muirhead, David Roberts, and Blake Wilelmi, and the figures were composed by Jeanette Mitchell.

\section{REFERENCES}

AMOROSO, E.C., EDHOLM, O.G. \& REWELL, R.E. 1947. Venous valves in the giraffe, okapi, camel, and ostrich. P. Zool. Soc. Lond. 117: 435-440.

DAGG, A.I. 1962. The role of the neck in the movements of the giraffe. J. Mammal. 43(1): 88-97.

GOETZ, R.H. \& KEEN, E.N. 1957. Some aspects of the cardiovascular system in the giraffe. Angiology 8: 542-564.

GOETZ, R.H., WARREN, J.V., GAUER, O.H., PATTERSON, J.L., DOYLE, J.T, KEEN, E.N. \& McGREGOR, M. 1960. Circulation of the giraffe. Circ. Res. 8: 1049-1058.

HARGENS, A.R., MILLARD, R.W., PETTERSSON, K. \& JOHANSEN, K. 1987. Gravitational haemodynamics and oedema prevention in the giraffe. Nature 329: $59-60$.

JOLY, N. \& LAVOCAT, A. 1846. Recherches historiques, zoologiques, anatomiques et palaeontologiques sur la giraffe. Mem. Soc. Mus. Hist. Nat. Strasb. 3: 1-112.

LAWRENCE, W.E. \& REWELL, R.E. 1948. The cerebral blood supply in the Giraffidae. P. Zool. Soc. Lond. 118: 202-212.

LLUCH, S., DIEGUEZ, G., GARCIA, A.L. \& GOMEZ, B. 1985. Rete mirabile of goat: its flow-damping effect on cerebral circulation. Am. J. Physiol.249: R482-R489.

MITCHELL, G. \& SKINNER, J.D. 1993. How giraffe adapt to their extraordinary shape. Trans. Roy. Soc. S. Afr. 48(2): 207-218.

MITCHELL, G. \& SKINNER, J.D. 2005. Giraffe thermoregulation: a review. Trans. Roy. Soc. S. Afr. 59(2): 49-57.

MITCHELL, G., BOBBITT, J.P. \& DEVRIES, S. 2008. Cerebral perfusion pressure in giraffe: modelling the effects of head-raising and -lowering. J. Theor. Biol. 252: 98-108.

SILVA, M.A., DEEN, K.I. FERNANDO, D.J.S. \& SHERIFFDEEN, A.H. 2002. The internal jugular vein valve may have a significant role in the prevention of venous reflux: evidence from live and cadaveric human subjects. Clin. Physiol. Funct. I. 22(3): 202-205.

THOMPSON, D.W. 1942. On growth and form. Cambridge University Press, Cambridge.

Corresponding Editor: E.Z. Cameron 